\title{
Research on Influence of Interesting Food Packaging Design on Consumer Psychology
}

\author{
Dan $\mathrm{Wu}$ \\ WENHUA COLLEGE, Wuhan, 430074, China
}

\begin{abstract}
Interesting food packaging design is based on the design of modern consumer psychology. Packaging interest can produce a series of impacts on consumer psychology, such as meeting the consumer's spiritual needs, prompting consumers'resonant psychology, or stimulate consumers to generate impulse to purchase. This paper analyzes the influences of the interesting food packaging design on the consumer psychology and points out the principles of the interesting food packaging design based on the consumer psychology to provide some references for the relative researchers.
\end{abstract}

Keywords:interesting packaging design, food packaging, consumer psychology

\section{Introduction}

Currently, packaging design has transformed from the protecting the goods, landscaping products, facilitating transportation and promoting the basic functions in the past into the characteristics of the times is more focused on the performance of personalized packaging design, multi angle and visual expression. In the production of homogenization, material products and cultural products are gradually from the centralized leading to change the form of diversification, modern consumer psychology and consumer interest and cultural interest becomes more rich and diverse, in order to function as the main demands of the products have been unable to meet the needs of the people, the subjective factors also interesting plays a more and more important role in today's design, designers should be more starting from the form of packaging, materials, graphics, colour and other aspectsto analyse the design of interest. Who has not only practical, interesting design and full of novelty, personality, emotional interaction design 
and increase the design gives more psychological sense, create a design that people moved, improve the design of affinity. The social and economic development, social competition is becoming increasingly fierce, more and more pressure in life, people need through a variety of ways to meet the spirit of pleasure and relaxation, consumption has become one of the means. Most of the time, people in the process of consumption and no specific consumption object, only through the shopping way to meet the specific needs of a spiritual realm, this product packaging design will stand out. At the same time, it provides the premise and foundation for the birth and development of the interesting food package design.

\section{Influence of interesting food packaging design on consumer psychology}

\subsection{Meet spiritual needs}

All interesting packagingdesign can give consumers a spiritual satisfaction. When this commodity can meet some psychological needs of consumers or represent a new concept, it will be able to seize the hearts of consumers. The commodity sales play a useful role in promoting. In the previous analysis of modern consumer psychology, we understand that people buy goods in order to meet their material needs and emotional needs. In modern consumption, people in the physiological needs are met more and more in modern consumption, people in the physiological needs are met more and more hope to meet emotional needs. In this process, packaging plays a role of media. In modern society, people live more and more quickly, life pressure is bigger, in this tense work and living environment people more eager to get relaxed and happy. So in the shopping process people want to get pleasure, which needs to be given through packaging. Commodity packaging in addition to the necessary protection for goods, but also through the realization of commodity packaging design interesting, to attract the attention of consumers. The pressure of people's work and life is increasing day by day, and shopping becomes the main way for people to gain spiritual enjoyment. It satisfies people's unique aesthetic pursuit, realizes the individual value of consumers, and brings spiritual satisfaction and joy to consumers. At the same time of relaxing the tension, packaging allows consumers to enjoy a relaxed and happy spirit.

\subsection{Trigger emotional response}

Packaging design is for people, which needs emotional blend. Designers grasp the emotional and artistic conception of packaging design, in order to better convey the design ideas and creativity, so that consumers understand and accept, packaging design is the true meaning of design life. Packaging design is a material practical activity, which cannot be separated from the emotional exchange of induction. Although the interesting packaging design is through the visual elements to show the goods, but it is not limited to the use of graphics, text, 
colour, texture, shape to express the features of the products, it is more important as the link between consumers and goods, put the two together, causing the attention of consumers, and consumers communicate emotion resonate with consumers. This is actually interesting design can make use of their own can bring the advantages of pleasure, so that packaging and consumers produce interactive emotional characteristics. The success of the interesting packaging design includes two aspects: one is the information commodity functional information. This is the most essential and most direct material packaging design to convey the information. It is the main reason for most people to buy goods. On the other hand, it is caused by the interesting interactive packaging emotional information. This is interesting packaging design to convey the internal, indirect, non-material aspects of information, but also consumers interact by the purchase motives and purchase interest, resulting in the purchase of product behaviour an important reason. Only the packagingproducing emotional resonance can really impress consumers.

\subsection{Stimulate purchasing interest}

Consumer interest is a complex psychological. Any kind of product and packaging can cause different people's interest and produce purchasing behaviour. Interest is a kind of psychological activity based on the special cognition and emotion tendency of the objective things. Consumers will prepare for future buying behaviours is also one of its performance. In general, when consumers are interested in a product, happiness, joy and satisfaction are often accompanied by emotion. In commercial design, improve the important link of the sales is out of consumer psychology, caused the audience's interest and appeal. The design of small volume lightweight cute and interesting, more popular with young people, although the capacity and price comparison, far from affordable big package, but still there will be a lot of people will choose to buy repeatedly because it is out of interest. The purchase of goods from our experience, we will find a lot of time to buy a product, often not out of the needs of the product, but its packaging attracted our attention, simply want to buy, different people have different desire to buy in different psychological needs. We buy this behaviour in the process, often by the appearance of packaging on the eyes of the visual temptation to produce a buying impulse, showing the uniqueness of the product packaging can stimulate consumer interest in the purchase. The market a large number of new hot selling products are endless every day, while existing goods are constantly redesigned to keep pace with the times, so as not to be eliminated by the market. From some examples of product marketing success, it is found that the main driving factors of consumer interest are consumer preferences and needs. Interesting packaging design can stimulate people's desire to buy from the appearance, beating many ordinary commodities. 


\section{Principles of interesting food packaging design based on consumer psychology}

\subsection{Individualization}

As everyone in the world has its own unique personality, interesting packaging design also has a unique product characteristics. In the increasingly fierce market competition today, no unique characteristics of their products can only be eliminated by society. So, the modern packaging design should avoid monotony, packaging designers must understand the product features and attributes, to continue to explore the packaging design originality in design innovation, to be innovative to smart, full of human. People in the design of the product, not blindly to pay attention to their own interests, the use of inferior materials and make the packaging of the product, but should design the products fully integrated packaging performance, so that products can be truly new in order to be different, talent shows itself. Under the impetus of need, personality can form and develop. And interest is essentially an embodiment of human aesthetic personality, can attract people's interest, thus triggering a certain need, thus forming a personality behavior process. People's choice of taste can be a taste of life. Consumers are keen on personalized design. Interesting design has become an important manifestation of the pursuit of taste and personality.

\subsection{Humanization}

One of the most important features of interest is its humanization. Humanity is the embodiment of the "people-oriented" feature, paying attention to the concern and respect for a person. It is to satisfy the basic needs of people on the basis in order to meet the pursuit of modern people relaxed, humorous and happy psychological need to produce. In the premise of diversification of modern design, to explore the design style can be said to be brilliant, which flowers bloom together, humanized design becomes a hot spot, and gradually formed a trend. If the product blocks human activity, the design fails; if the product makes people feel safer, more comfortable, more efficient, happier, the design succeeds. The pursuit of design is also a manifestation of human interest. It focuses on people's feelings, through interesting design to convey relaxed, happy thought, so as to meet the needs of modern human feelings. In the ever-changing world, people have begun to gradually shift their needs to the product above, hoping to get a satisfaction. The ultimate goal of packaging design is people, so what kind of message, what kind of a way to transfer, should be human centered design products should be good to touch people's hearts, to stimulate people's desire to buy.

\subsection{Securitization}

The rapid development of the worldputs people into a rich and colorful world of goods. The products have been from single to diversity, to meet the needs of the 
people by the initiative to create demand, which also makes products from development to sales, which must go through security channels quickly and effectively. The ultimate goal of product design is to ensure the safety of the product. The product must be designed to ensure that the product itself will not bring personal harm to consumers. The enterprise in the production of products must do safety inspection work, to all aspects of the safety supervision of the products, all activities must be based on ensuring consumer life safety to improve the social and economic benefits of the real.

\section{Conclusion}

With the rapid development of economy, the market competition is more and more fierce. People's consumption psychology and consumption concept have also undergone significant changes. Consumers are no longer blindly herd in the consumer market, but have the ability to enjoy life independently. Interesting food packaging design can be very conductive to reduce people's daily life pressure, to cause emotional resonance and to stimulate consumers to generate impulse to purchase. The design of interesting food packaging brings great economic benefits to the society.

\section{References}

[1] Zhang Chunrong, On Interaction and Interesting in Product Packaging Design, The World and Chongqing, 7(7), pp. 106-110, 2016

[2]Jay Singh, SanjivJaggia, KoushikSaha, The Effect of Distribution on Product Temperature Profile in Thermally Insulated Containers for Express Shipments, Packaging technology and science, 32(5), pp. 61-64, 2013

[3]Wang Anxia, Deng Li, Discussion on Interesting Packaging Design from Consumption Psychology, Packaging Engineering, 28(11), pp. 151-153,2007

[4]He Xia, Wang Jiajun, Interesting Packaging Design, Packaging Engineering, 27(6), pp. 56-57, 2006

[5]Wang Wenqin, Analysis of the Complementary Effect and Consumer Psychology of Children's Food Packaging, Design, 29(3), pp. 140-141, 2016

[6]Li Ling, The Theory of the Interesting Packaging Design Ideas, Art and Design, 14(1), pp.33-35, 2016

[7]Zhu Xiaolin, Wang Kunqian, XuRenping, Discussion on Interesting Packaging Design Strategy, Packing Engineering, 28(6), pp. 162-164, 2007

[8]Yu Ying, Wu Yi, The Color Psychology and Humanized Design for Food Packaging, Design, 28(11), pp. 156-157, 2015

[9]S Sanuja, A Agalya, MJ Umapathy, Synthesis and characterization of zinc oxide-neem oil-chitosan bionanocomposite for food packaging application, International Journal of Biological Macromolecules, 74(5), pp. 76-84, 2015

[10]Ma Geng, Food Packaging Design Based on Child Psychology and Cognition, Packing Engineering, 36(10), pp. 93-96, 2015 